\title{
Autoimmune Hemolytic Anemia After Cyanocobalamin Replacement in a Patient With a Previous Diagnosis of Pernicious Anemia: A Case Report
}

Leonardo Mejia Buritica ${ }^{1}$, Jesus Zapata Alvarez ${ }^{2}$, Lissette Vergara Ouintero ${ }^{2}$, Juan Pablo Villegas Molina 2 , José Domingo Torres Hernandez ${ }^{1}$

1. Department of Hematology, Universidad de Antioquia, Medellin, COL 2. Department of Internal Medicine, Universidad de Antioquia, Medellin, COL

Corresponding author: Leonardo Mejia Buritica, leonardo.mejiab@udea.edu.co

\begin{abstract}
Pernicious anemia (PA) is associated with other autoimmune diseases, such as hypothyroidism, type 1 diabetes mellitus (DM1), Addison's disease, and vitiligo. The association between PA and autoimmune hemolytic anemia (AIHA) is rare, with less than 30 cases reported in the literature. In this paper, we report a case of a patient with a confirmed diagnosis of PA, who, six months after starting treatment with cyanocobalamin, presented with severe hemolysis with a positive direct antiglobulin test (DAT) for warm antibodies; the patient responded well to glucocorticoid treatment. AIHA in PA patients can be triggered by cyanocobalamin replacement due to the expression of membrane antigens by mature red blood cells entering into the peripheral circulation. This association should be considered because these patients, in addition to cyanocobalamin replacement, will require immunosuppressive treatment, usually with glucocorticoids.
\end{abstract}

Review began 09/24/2020 Review ended 10/01/2020 Published 10/05/2020

\section{() Copyright 2020}

Mejia Buritica et al. This is an open access article distributed under the terms of the Creative Commons Attribution License CC-BY 4.0., which permits unrestricted use, distribution, and reproduction in any medium, provided the original author and source are credited.
Categories: Internal Medicine, Hematology

Keywords: autoimmune hemolytic anemia (aiha), pernicious anemia, direct antiglobulin test, coombs test

\section{Introduction}

Vitamin B12 deficiency is a common cause of megaloblastic anemia, and it occurs in more than $16 \%$ of patients with macrocytosis [1-2]. The prevalence increases with age, being more frequent in patients older than 60 years, but it can affect the younger population as well [3]. There are multiple causes of vitamin B12 deficiency, with pernicious anemia (PA) being one of the most prevalent [4]. PA is a disease of autoimmune origin in which antibodies attack the parietal cells of the stomach or intrinsic factor, and presents as atrophic gastritis, anemia, and neurological manifestations [5]. PA is associated with other autoimmune diseases, such as hypothyroidism, type 1 diabetes mellitus (DM1), Addison's disease, and vitiligo [6].

The association between PA and autoimmune hemolytic anemia (AIHA) is rare, with only a few cases described in the literature [2]. In this paper, we present the case of a patient with a confirmed diagnosis of PA, who developed severe AIHA with a positive direct antiglobulin test (DAT) for warm antibodies after the initiation of cyanocobalamin replacement.

\section{Case Presentation}

A 56-year-old man, with no significant medical history, presented to the emergency department with a twomonth history of asthenia, adynamia, and weight loss. Two hours prior to the admission, he had felt abdominal pain in the right upper quadrant. The physical examination was remarkable for tenderness in the right upper quadrant and generalized mucocutaneous pallor. Acute cholecystitis was diagnosed, and laparoscopic cholecystectomy was performed without complications.

Laboratory tests on admission showed macrocytic anemia, vitamin B12 deficiency, and low reticulocytes (Table 1). Intrinsic factor antibodies were positive. A digestive endoscopy was performed, which revealed macroscopic atrophic gastritis. The gastric biopsy showed chronic atrophic gastritis, decreased parietal cells, and reduction of fundic glands. The diagnosis of PA was confirmed, and treatment was started with cyanocobalamin 1 milligram intramuscular (IM) daily for two weeks and then 1 milligram IM monthly, which led to the resolution of anemia and improvement of symptoms. 


\section{Cureus}

\begin{tabular}{|c|c|c|c|c|}
\hline Test & Reference range & Initial value & $\begin{array}{l}\text { Six months } \\
\text { later }\end{array}$ & $\begin{array}{l}\text { Two weeks after glucocorticoid } \\
\text { treatment }\end{array}$ \\
\hline Hemoglobin & $14-18 \mathrm{~g} / \mathrm{dL}$ & $9.7 \mathrm{~g} / \mathrm{dL}$ & $5.4 \mathrm{~g} / \mathrm{dL}$ & $8.4 \mathrm{~g} / \mathrm{dl}$ \\
\hline Hematocrit & $42-50 \%$ & $26.4 \%$ & $16.7 \%$ & $23.8 \%$ \\
\hline $\begin{array}{l}\text { Mean corpuscular } \\
\text { volume }\end{array}$ & 80-98 fL & $115.3 \mathrm{fL}$ & $127.5 \mathrm{fL}$ & $110 \mathrm{fL}$ \\
\hline Platelet count & $\begin{array}{l}150,000- \\
450,000 / \text { microL }\end{array}$ & 313,000/microL & $387,000 / \mathrm{microL}$ & 430,000/microL \\
\hline Leukocyte count & $4,000-11,000 / \mathrm{microL}$ & 9,850/microL & 11,150/microL & 9,000/microL \\
\hline Reticulocyte count & $0.5-1.5 \%$ & $1.32 \%$ & $22.8 \%$ & \\
\hline Total bilirubin & $0.3-1 \mathrm{mg} / \mathrm{dL}$ & $2.59 \mathrm{mg} / \mathrm{dl}$ & $2.48 \mathrm{mg} / \mathrm{dl}$ & $1.32 \mathrm{mg} / \mathrm{dl}$ \\
\hline Direct bilirubin & $0.1-0.3 \mathrm{mg} / \mathrm{dL}$ & $1.22 \mathrm{mg} / \mathrm{dl}$ & $0.96 \mathrm{mg} / \mathrm{dl}$ & $0.59 \mathrm{mg} / \mathrm{dl}$ \\
\hline Vitamin B12 & $200-800 \mathrm{pg} / \mathrm{mL}$ & $93.59 \mathrm{pg} / \mathrm{mL}$ & $412 \mathrm{pg} / \mathrm{mL}$ & \\
\hline Lactate dehydrogenase & $80-225$ units/L & 526 units/L & 860 units/L & 424 units/L \\
\hline Ferritin & $24-336 \mathrm{ng} / \mathrm{mL}$ & & $425 \mathrm{ng} / \mathrm{L}$ & \\
\hline DAT & Negative & Negative & Positive 4+ & \\
\hline Intrinsic factor antibodies & $\leq 10.0$ units $/ \mathrm{mL}$ & 47.6 units $/ \mathrm{mL}$ & & \\
\hline HIV test & Negative & & Negative & \\
\hline Non-treponemal test & Negative & & Negative & \\
\hline Hepatitis $\mathrm{C}$ antibodies & Negative & & Negative & \\
\hline HBsAg & Negative & & Negative & \\
\hline
\end{tabular}

\section{TABLE 1: Laboratory tests}

DAT: direct antiglobulin test; HIV: human immunodeficiency virus; HBsAg: hepatitis B surface antigen

Six months later, the patient presented again to the emergency department with a two-week history of asthenia, adynamia, dizziness, exertional dyspnea, and headache. The physical examination was remarkable for a temperature of 38 degrees Celsius, generalized mucocutaneous paleness, and jaundice. The laboratory test revealed severe anemia (Table 1), and red blood cell transfusion was ordered. Nevertheless, the blood transfusion could not be performed due to positive cross matches with all the units available in the blood bank.

A contrasted CT of the chest and abdomen was performed, which showed hepatomegaly and mild splenomegaly (Figure 1) without other significant findings; and a bone marrow aspiration and biopsy were performed, which reported erythroid hyperplasia without other alterations. Also, there was no evidence of lymphoid neoplasia on flow cytometry. 


\section{Cureus}

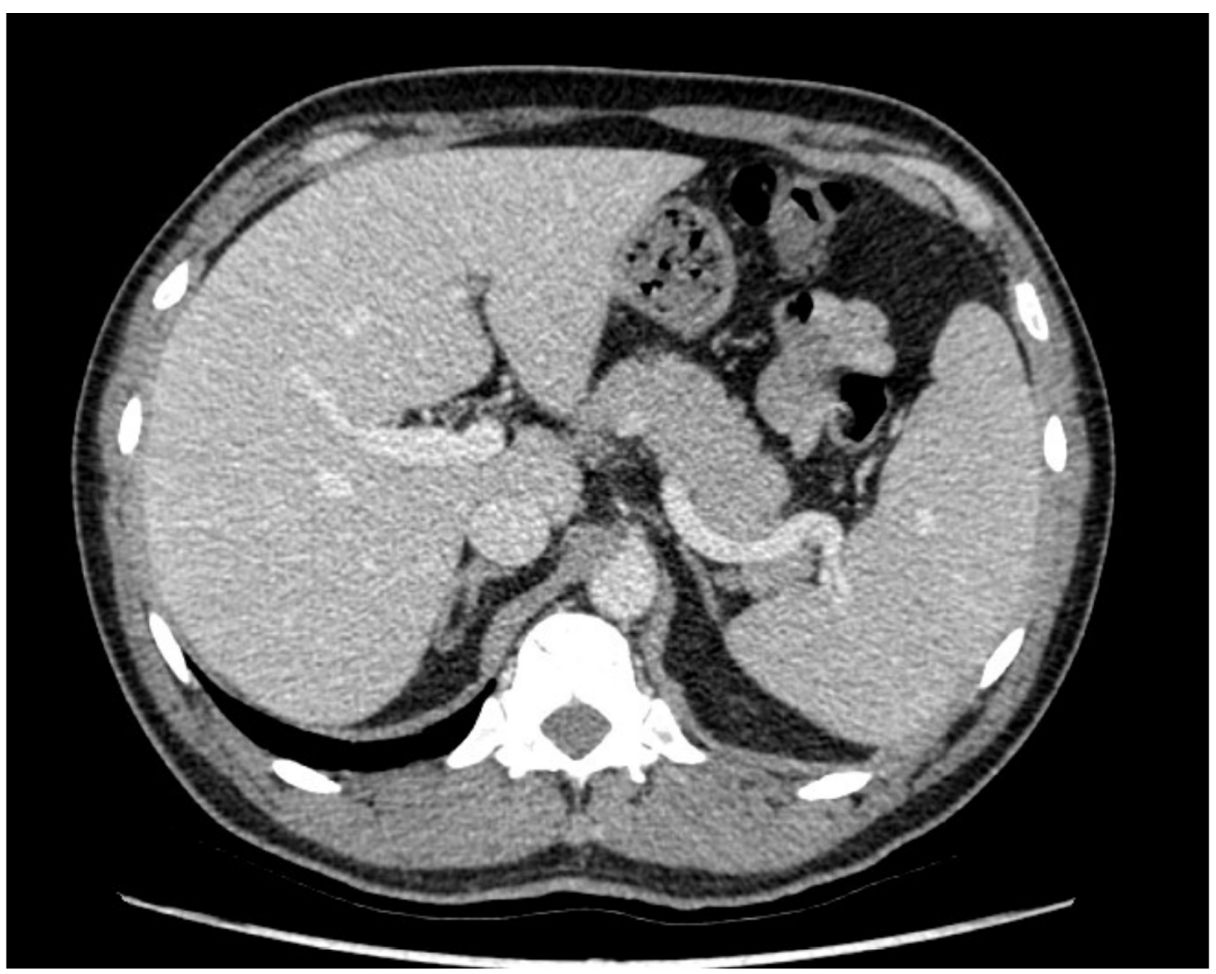

FIGURE 1: Computed tomography scan showing an enlarged liver and spleen

Vitamin B12 levels were normal, and DAT was strongly positive for warm antibodies (Figure 2). A diagnosis of warm-AIHA was established and treatment with prednisolone at $1 \mathrm{mg} / \mathrm{kg} / \mathrm{day}$ was started.

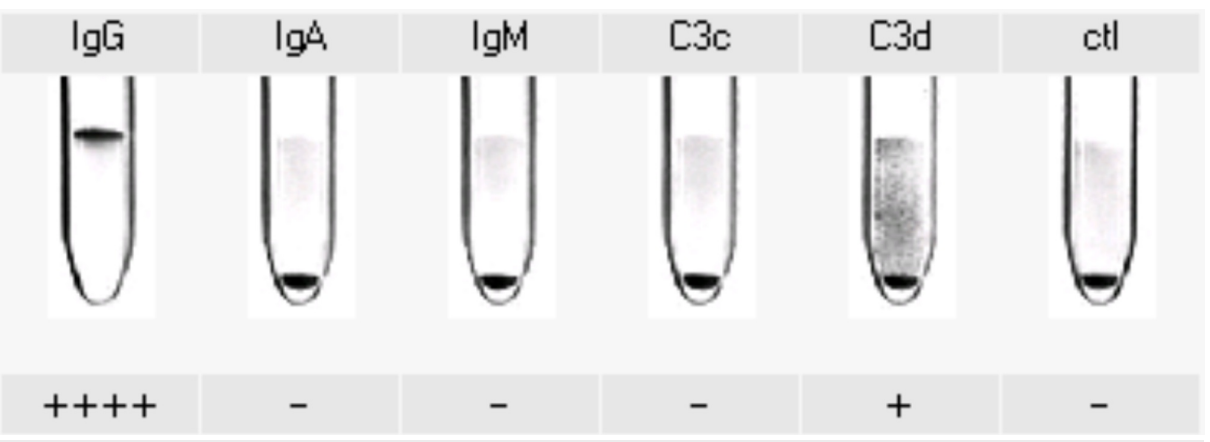

FIGURE 2: Monospecific direct antiglobulin test positive for IgG and C3d

IgG: immunoglobulin G; IgA: immunoglobulin A; IgM: immunoglobulin M; C3 complement fraction 3; ctl: control

Two weeks after the start of treatment with glucocorticoids, lactate dehydrogenase (LDH) levels decreased, hemoglobin improved, and the patient was discharged with oral prednisolone therapy, with an outpatient reduction dose plan. Cyanocobalamin replacement was continued.

\section{Discussion}

Anemia is a frequent clinical finding in daily medical practice and can be caused by multiple etiologies [7]. Vitamin B12 deficiency is a frequent cause of megaloblastic anemia [1], and PA is one of the most important causes of this condition. The association between PA and other autoimmune diseases is well recognized [6]; however, very few cases of coexistence between PA and AIHA have been reported in the literature [2]. To our knowledge, less than 30 cases have been reported in the literature of patients with a diagnosis of both diseases, and it is more frequent in middle-aged women with other autoimmune diseases [2]. 
characterized by the destruction of red blood cells mediated by autoantibodies directed against antigens present in their membrane [9]. This disease may appear in isolation, also called primary AIHA, or it can be associated with other autoimmune diseases. AIHA could also be associated with primary immunodeficiencies, infectious diseases, and neoplastic disorders [10]. In our case, no other autoimmune or neoplastic diseases were identified. However, in other cases described in the literature, coexistence with other autoimmune diseases has been found, such as hypothyroidism, systemic lupus erythematosus, alopecia areata, vitiligo, and rheumatoid arthritis [2].

From a serological point of view, various forms of AIHA have been described. The most common form is produced by immunoglobulin G (IgG) type antibodies that bind to red blood cells at 37 degrees Celsius, and mainly cause extravascular hemolysis [9]. This form is called warm-AIHA and accounts for 65-70\% of AIHA cases [10].

The second most common form is called cold AIHA and accounts for 20-25\% of cases [10]. This type of hemolytic anemia is mediated by immunoglobulin M (IgM) type antibodies that bind to membrane antigens at temperatures lower than body temperature, optimally 4 degrees Celsius in vitro [8]. The responsible immunoglobulin can be polyclonal or monoclonal, the latter present in lymphoproliferative neoplasms such as chronic lymphocytic leukemia, Waldenstrom macroglobulinemia, and other non-Hodgkin lymphomas [11].

For the diagnosis of AIHA, the DAT test (also known as the Coombs test) is required, which is positive in most cases (only $5 \%$ of patients with AIHA are DAT-negative) [12]. When DAT is positive in a patient with overt hemolytic anemia with increased reticulocytes, indirect hyperbilirubinemia, increased LDH, and low haptoglobin, the diagnosis of AIHA is highly likely [13]. However, DAT can also be positive in individuals without hemolysis, being detected in $2 \%$ of the normal population [14].

Two types of DAT are available, polyspecific and monospecific. Polyspecific DAT simultaneously detects IgG and complement fraction 3 (C3), and it is the screening test for suspected AIHA [15]. If polyspecific DAT is positive, then monospecific DAT should be performed, which contains specific antibodies that bind to IgG, immunoglobulin A (IgA), IgM, and complement fractions C3c and C3d. This test classifies AIHA as warm antibodies (IgG +/- C3) or cold antibodies (IgM or C3) [16]. Mixed AIHA has also been described in cases expressing both warm and cold antibodies [17].

In patients with PA, DAT may be transiently positive when there is no adequate replacement of cyanocobalamin. These cases can be easily differentiated from AIHA since they present with low reticulocytes, and anemia improves rapidly after the initiation of cyanocobalamin replacement, and DAT becomes negative with treatment [18-19]. On the other hand, patients with AIHA usually present with increased reticulocytes and anemia does not improve until the start of immunosuppressive treatment, usually with glucocorticoids. Prophylactic folic acid is also indicated because active hemolysis can consume folate and cause megaloblastosis [2]. In our case, the initial DAT was negative, and the reticulocytes increased after cyanocobalamin replacement. Furthermore, the hemolysis improved with glucocorticoids, which clearly demonstrates the autoimmune origin of red blood cell destruction.

Some cases in which AIHA starts after cyanocobalamin replacement have also been reported. Vucelić et al. reported a patient with vitamin B12 deficiency, who, eight days after cyanocobalamin replacement, presented with worsening of hemolysis and the DAT became positive; treatment with glucocorticoids was started with improvement of hemolysis [20]. Our case is remarkable because the clinical manifestations of hemolysis began six months after cyanocobalamin replacement.

The mechanisms that explain autoimmune hemolysis in patients with PA are not clear. It is proposed that the treatment of PA causes the mature red blood cells to express membrane antigens and enter into peripheral circulation where they are attacked by self-reactive antibodies, triggering autoimmune hemolysis [20]. However, this will only occur in individuals with a previously established background of autoimmunity.

\section{Conclusions}

PA is an autoimmune disease clearly associated with other antibody-mediated diseases. The association between PA and AIHA is rare, with only a few cases reported in the literature. Our case was remarkable because of the manifestation of AIHA six months after the treatment with cyanocobalamin in a patient with PA. We hope this paper will prompt clinicians to consider the diagnosis of AIHA in any patient with PA who presents with worsening anemia, high reticulocytes, and positive DAT after starting treatment with cyanocobalamin. In these cases, immunosuppressive treatment, mainly with glucocorticoids, must be started quickly.

\section{Additional Information}

\section{Disclosures}

Human subjects: Consent was obtained by all participants in this study. Conflicts of interest: In 
compliance with the ICMJE uniform disclosure form, all authors declare the following: Payment/services info: All authors have declared that no financial support was received from any organization for the submitted work. Financial relationships: All authors have declared that they have no financial relationships at present or within the previous three years with any organizations that might have an interest in the submitted work. Other relationships: All authors have declared that there are no other relationships or activities that could appear to have influenced the submitted work.

\section{Acknowledgements}

We thank Catalina Gomez Piedrahita from the Hospital San Vicente Fundación blood bank service.

\section{References}

1. Stouten K, Riedl JA, Droogendijk J, et al.: Prevalence of potential underlying aetiology of macrocytic anaemia in Dutch general practice. BMC Fam Pract. 2016, 17:113. 10.1186/s12875-016-0514-z

2. Yeruva SL, Manchandani RP, Oneal P: Pernicious anemia with autoimmune hemolytic anemia: a case report and literature review. Case Rep Hematol. 2016, 2016:7231503. 10.1155/2016/7231503

3. Andrès E, Loukili NH, Noel E, et al.: Vitamin B12 (cobalamin) deficiency in elderly patients . CMAJ. 2004, 171:251-259. 10.1503/cmaj.1031155

4. Carmel R: Prevalence of undiagnosed pernicious anemia in the elderly . Arch Intern Med. 1996, 156:10971100. 10.1001/archinte.1996.00040041097008

5. Toh BH: Pathophysiology and laboratory diagnosis of pernicious anemia . Immunol Res. 2017, 65:326-330. 10.1007/s12026-016-8841-7

6. Lenti MV, Rugge M, Lahner E, et al.: Autoimmune gastritis. Nat Rev Dis Primers. 2020, 6:56. 10.1038/s41572-020-0187-8

7. Tefferi A: Anemia in adults: a contemporary approach to diagnosis . Mayo Clin Proc. 2003, 78:1274-1280. 10.4065/78.10.1274

8. Hill QA, Stamps R, Massey E, Grainger JD, Provan D, Hill A: The diagnosis and management of primary autoimmune haemolytic anaemia. Br J Haematol. 2017, 176:395-411. 10.1111/bjh.14478

9. Hill A, Hill QA: Autoimmune hemolytic anemia. Hematology Am Soc Hematol Educ Program. 2018, 2018:382-389. 10.1182/asheducation-2018.1.382

10. Liebman HA, Weitz IC: Autoimmune Hemolytic Anemia. Med Clin North Am. 2017, 101:351-359. 10.1016/j.mcna.2016.09.007

11. Barcellini W, Fattizzo B: The changing landscape of autoimmune hemolytic anemia . Front Immunol. 2020, 11:946. 10.3389/fimmu.2020.00946

12. Takahashi T: Direct antiglobulin test-negative autoimmune hemolytic anemia . Acta Haematol. 2018, 140:18-19. 10.1159/000489253

13. Chaudhary RK, Das SS: Autoimmune hemolytic anemia: from lab to bedside . Asian J Transfus Sci. 2014, 8:512. 10.4103/0973-6247.126681

14. Gorst DW, Rawlinson VI, Merry AH, Stratton F: Positive direct antiglobulin test in normal individuals. Vox Sang. 1980, 38:99-105. 10.1111/j.1423-0410.1980.tb02337.x

15. Parker V, Tormey CA: The direct antiglobulin test: indications, interpretation, and pitfalls . Arch Pathol Lab Med. 2017, 141:305-310. 10.5858/arpa.2015-0444-RS

16. Jäger U, Barcellini W, Broome CM, et al.: Diagnosis and treatment of autoimmune hemolytic anemia in adults: recommendations from the First International Consensus Meeting. Blood Rev. 2020, 41:100648. 10.1016/j.blre.2019.100648

17. Brodsky RA: Warm autoimmune hemolytic anemia . N Engl J Med. 2019, 381:647-654. 10.1056/NEJMcp1900554

18. Rabinowitz AP, Sacks Y, Carmel R: Autoimmune cytopenias in pernicious anemia: a report of four cases and review of the literature. Eur J Haematol. 1990, 44:18-23. 10.1111/j.1600-0609.1990.tb00341.x

19. Todo S, Okamoto K, Sugimoto T, et al.: A case of pernicious anemia requiring differential diagnosis of autoimmune hemolytic anemia complication. Oxf Med Case Reports. 2017, 2017:omx053. 10.1093/omcr/omx053

20. Vucelić V, Stancić V, Ledinsky M, et al.: Combined megaloblastic and immunohemolytic anemia associated-a case report. Acta Clin Croat. 2008, 47:239-243. 